\title{
Proteasomal System Related Stress Response in Different Cancer Cell Lines
}

\author{
Ayse Tarbin Jannuzzi ${ }^{1}$ (D), Sema Arslan ${ }^{2}$ (D), Buket Alpertunga ${ }^{1}$ (D), Betul Karademir Yilmaz ${ }^{2}$ (D) \\ ${ }^{1}$ Istanbul University, Faculty of Pharmacy, Department of Pharmaceutical Toxicology, Istanbul, Turkey. \\ ${ }^{2}$ Marmara University, School of Medicine, Department of Biochemistry / Genetic and Metabolic Diseases Research and Investigation Center, Istanbul, Turkey. \\ Correspondence Author: Betul Karademir Yilmaz \\ E-mail: betulkarademir@marmara.edu.tr \\ Received: $30.09 .2020 \quad$ Accepted: 03.12 .2020
}

\begin{abstract}
Objective: Proteasomal system is the primary protein degradation mechanism and important for cellular homeostasis. On the other hand, increased proteasome activity protects cancer cells from cell death. The objective of this preliminary study was to determine the response of the proteasomal system to oxidative stress in human cancer cell lines including K562 chronic myelogenous leukemia, U251 glioblastoma, DU145 prostate cancer, HepG2C3A hepatoma, and MCF7 breast cancer.

Methods: Cells were exposed to hydrogen peroxide ( $\mathrm{H} 2 \mathrm{O} 2$ ) as a stressor. $20 \mathrm{~S}$ and $26 \mathrm{~S}$ proteasome activities and K48-linked protein ubiquitination levels were determined immediately and 3 hours after exposure.

Results: As an immediate response, 20S proteasome activities decreased in only K562 and U251 cells and 20S+26S proteasome activities decreased only in $\mathrm{K} 562$ cells. Following $3 \mathrm{~h}$ of incubation, all cells showed a significant decrease in both $20 \mathrm{~S}$ and $20 \mathrm{~S}+26 \mathrm{~S}$ proteasome activities. K48-linked protein ubiquitination levels increased immediately in K562 and DU145 cells. After $3 \mathrm{~h}$ of incubation, ubiquitination levels increased in all cell lines except MCF7 cells.
\end{abstract}

Conclusion: The difference in the response of the proteasomal system to stress could be the reason for differential adaptation to oxidative stress in different cancer types.

Keywords: Proteasome activity, 20S proteasome, 265 proteasome, oxidative stress, cancer

\section{INTRODUCTION}

All cells need energy to maintain normal cell function and primarily cells generate free energy in the form of adenosine5 '-triphosphate (ATP) via oxidative phosphorylation and glycolysis (1). According to oxygen availability, cellular dynamics of energy shifts and in the normoxic conditions, the main energy source is oxidative phosphorylation while under hypoxic conditions, glycolysis serves as the primary pathway to produce energy to compensate weakened oxidative phosphorylation (2). In contrast to normal cells, most cancer cells rely on glycolysis for energy production and this phenomenon is known as the Warburg Effect (3). Generation of reactive oxygen species (ROS) is a consequence of aerobic metabolism and ROS function as signaling molecules to regulate a wide variety of physiologic conditions at low concentrations (4). The imbalance between generation and scavenging of ROS results disturbances in cellular signaling pathways and causes oxidative stress (5). The Warburg effect plays a role in the upregulation of redox homeostasis and causes alterations in mitochondrial redox potential in cancer cells (3). Many cancer cells have increased ROS levels, however it is not clear if mutations in oncogenes cause an increment in ROS production or affect the levels of antioxidant proteins (6). ROS can cause oxidative modifications of the proteins and these modifications can affect their function and/or activity $(7,8)$. Degradation of oxidized proteins is important for maintaining cellular homeostasis and the proteasomal system plays a very important role in the degradation pathway $(7,9)$.

Proteasome is a multicatalytic complex, which is responsible for turnover of most of the cellular short-lived, unnecessary, oxidized and damaged proteins. The proteolytic part of the proteasome is the $20 \mathrm{~S}$ core particle. $20 \mathrm{~S}$ proteasome is barrel-like shaped and consists of two stacked heptameric outer $\alpha$ rings and two inner $\beta$ rings which has catalytically active sites: $\beta 1$ (caspase-like), $\beta 2$ (trypsin-like) and $\beta 5$ (chymotrypsin-like) (10). Several regulatory particles can bind to $20 \mathrm{~S}$ proteasome and $19 \mathrm{~S}$ regulatory particle is among them. When 205 proteasome binds one or two 19S subunits, forms $26 \mathrm{~S}$ and $30 \mathrm{~S}$ proteasome, respectively (Hereafter 
referred as 265 proteasome), (11). Substrate degradation by $26 \mathrm{~S}$ proteasome is ATP and ubiquitin-dependent, and polyubiquitin conjugation to a target protein via lysine 48 (K48) is characterized as an essential step for $26 \mathrm{~S}$ proteasome degradation $(12,13)$. 195 regulatory particle has functions in substrate recognition, deubiquitination, unfolding and it interacts with $20 S$ catalytic core to promote opening $\alpha$ ring and transfer of substrates to catalytically active sites $(14,15)$. While $20 \mathrm{~S}$ proteasome does not bind 195 particle, it preferably degrades oxidized proteins and this degradation is ATP and ubiquitination independent $(16,17)$. This selective removal of the oxidized proteins by the 205 proteasome plays a crucial role in antioxidant defense against oxidative stress (18). Under oxidative stress conditions, 265 proteasome dissociates into free 195 regulatory particle and 205 core particle, thus free $20 \mathrm{~S}$ proteasomes can rapidly degrade oxidatively damaged proteins to maintain cellular function (7). Besides, this dissociation is reversible and after a certain period of time 195 regulatory particle and 205 core particle can associate and regenerate $26 \mathrm{~S}$ proteasome (19).

Cancer cells have increased proteasomal activity due to altered protein homeostasis $(20,21)$. Adaptation to oxidative stress can protect cancer cells from apoptotic and/or necrotic cell death $(22,23)$. Some studies demonstrated that, cancer cells have significant upregulation in proteasomal pathways compared to normal cells and therefore cancer cells are more prone to proteasome inhibition than normal cells $(24,25)$. This situation also brings the question of proteasomal response to chemotherapy and radiotherapy-induced stress and the role of the proteasomal system in cancer therapy resistance.

Despite extensive research on proteasomal regulation in oxidative stress conditions, there is not enough information about proteasome activation in different cancer cell lines. To address that, we aimed to investigate differential $20 \mathrm{~S}$ and $26 \mathrm{~S}$ proteasome activities and K48-linked protein ubiquitination as early (immediate activity measurement) and late (activity measurement following $3 \mathrm{~h}$ of incubation) response after oxidative stress in different cancer cell lines.

\section{METHODS}

\subsection{Materials and chemicals}

Human chronic myelogenous leukemia K562 (CCL-243), human glioblastoma U251, human prostate cancer DU145 (HTB-81), human hepatoma HepG2C3A (CRL-10741), human breast cancer MCF-7(HTB-22) cells were purchased from American Type Culture Collection (ATCC) (Rockville, MD, USA). Dulbecco's modified Eagle's medium (DMEM), fetal bovine serum (FBS), penicillin-streptomycin solution were purchased from Gibco (Grand Island, NY, USA). Suc-LeuLeu-Val-Tyr-MCA substrate and 2-Deoxy-D-glucose were from Glentham Life Sciences (Corsham, UK). Hydrogen peroxide $\left(\mathrm{H}_{2} \mathrm{O}_{2}\right)$, saccharose, HEPES, magnesium chloride $\left(\mathrm{MgCl}_{2}\right)$, dithiothreitol, ethylenediaminetetraacetic acid (EDTA), adenosine 5'-triphosphate disodium salt hydrate
(ATP), hexokinase were purchased from the Sigma Chemical Company (St Louis, MO, USA). BCA protein assay kit was from Thermo Scientific (Fremont, CA, USA).

\subsection{Cell Culture}

K562, U251, DU145, HepG2C3A and MCF7 cells were cultured in Dulbecco's modified Eagle's medium (DMEM) supplemented with $10 \%$ fetal bovine serum (FBS), $100 \mathrm{U} /$ $\mathrm{mL}$ penicillin-streptomycin at $37^{\circ} \mathrm{C}, 5 \% \mathrm{CO}_{2}$. The cells were routinely passaged in the condition of $\sim 80 \%$ confluency.

\section{3. $\mathrm{H}_{2} \mathrm{O}_{2}$-treatment and recovery procedure}

Cells were divided into 3 treatment groups as PBS (Control), $\mathrm{H}_{2} \mathrm{O}_{2}$ (Oh time point) and $\mathrm{Rec}-\mathrm{H}_{2} \mathrm{O}_{2}$ (3h time point). For the treatment procedure, $2 \times 10^{6}$ cells were seeded in four different $100 \mathrm{~mm}$ dishes and left overnight. Then, the medium was aspirated and the cells were treated with freshly prepared $1 \mathrm{mM} \mathrm{H}_{2} \mathrm{O}_{2}$ in PBS with $\mathrm{Ca}^{++}$and $\mathrm{Mg}^{++}$for 30 min. The control group received just PBS with $\mathrm{Ca}^{++}$and $\mathrm{Mg}^{++}$for $30 \mathrm{~min}$. At the end of the exposure time, the cells were collected with trypsinization and washed with PBS (Oh time point). To study the late response, the cells were incubated with DMEM supplemented with $10 \%$ FBS, $100 \mathrm{U} /$ $\mathrm{mL}$ penicillin-streptomycin at $37^{\circ} \mathrm{C}, 5 \% \mathrm{CO}_{2}$ for 3 hours (h) directly after $\mathrm{H}_{2} \mathrm{O}_{2}$ treatment ( $3 \mathrm{~h}$ time point). Then, the cells were collected with trypsinization and washed two-times with PBS.

\subsection{Proteasome activity}

The cell pellets were suspended in lysis buffer $(0.25 \mathrm{M}$ saccharose, $25 \mathrm{mM}$ Hepes, $10 \mathrm{mM} \mathrm{MgCl}$, $1 \mathrm{mM}$ EDTA, and 1 $\mathrm{mM}$ dithiothreitol; $\mathrm{pH7.4)}$ and lysed by 3 times freeze-thaw cycles. The cell lysates were centrifuged at $14,000 \times \mathrm{g}$ for 30 min at $4{ }^{\circ} \mathrm{C}$. Supernatants were transferred in clean tubes and kept on ice until further analysis, which has been done as soon as possible in the same day. Freeze-thaw of cell lysates are not recommended for proteasome activity analyses.

Fluorogenic peptide substrate suc-Leu-Leu-Val-TyrMethylcoumarin (suc-LLVY-MCA) was used to determine proteasome $\beta 5$ chymotrypsin-like activity. The cell lysates were incubated with suc-LLVY-MCA in buffer containing 225 $\mathrm{mM}$ Tris, $45 \mathrm{mM} \mathrm{KCl}, 7.5 \mathrm{mM} \mathrm{Mg}\left(\mathrm{CH}_{3} \mathrm{COO}\right)_{2}, 7.5 \mathrm{mM} \mathrm{MgCl}$ and $1 \mathrm{mM}$ DTT, pH 7.8 for $30 \mathrm{~min}$ at $37{ }^{\circ} \mathrm{C}$. 20S proteasome activity was measured under ATP depleted conditions with the addition of $5 \mathrm{U}$ hexokinase and $15 \mathrm{nM}$ 2-Deoxy-D-glucose. To measure ATP-dependent proteasome activity $2 \mathrm{mM}$ ATP was added into the reaction mixture. Fluorescence intensity of released MCA was measured in a black 96-well plate at 360 $\mathrm{nm}$ excitation and $460 \mathrm{~nm}$ emission wavelengths. Free MCA standards were used to calculate the proteasome activity. Protein concentrations were measured with BCA assay and data were normalized to the protein concentrations and minute. 


\subsection{Western blot}

Cells were lysed in Cell Lysis Buffer (Cell Signalling Tech. 9803) and lysates were loaded on $12 \%$ SDS-PAGE gels then transferred to nitrocellulose membranes. Ponceau $S$ stain was applied to confirm equal protein loading. Membranes were blocked with blocking buffer, which contains $5 \%$ non-fat dry milk in TBST for $1 \mathrm{~h}$. The membranes were incubated with K48-linkage Specific Polyubiquitin Antibody (Cell Signaling Tech. 4289S, 1:1000 dilution in blocking buffer) for overnight at $+4{ }^{\circ} \mathrm{C}$. Then, the membranes were washed 3 times with TBST and incubated with HRP conjugated secondary antibody (Calbiochem, D0016365, 1:10000 dilution in blocking buffer) at room temperature for $2 \mathrm{~h}$. Finally, the membranes were screened through ChemiDoc chemiluminescence imaging system (Bio-Rad, USA).

\subsection{Statistical analysis}

All statistical analyses were performed using the Prism 7 software (Graph-Pad, CA, USA). Data are given as means \pm S.D. and significance was indicated as $p<0.05, p<0.01$ and $p<0.001$.

\section{RESULTS}

We measured proteasome activity in ATP depleted (20S) and ATP stimulated ( $20 \mathrm{~S}$ and $26 \mathrm{~S}$ ) conditions to elucidate the different responses of proteasome activities to oxidative stress in different cancer cell lines. We tested the activities in two different time points ( $\mathrm{h}$ and $3 \mathrm{~h}$ after treatments) to see the immediate (early) and late response. In general, ATP stimulated $20 \mathrm{~S}+26 \mathrm{~S}$ proteasome activity was found to be more prone to $\mathrm{H}_{2} \mathrm{O}_{2}$ induced stress condition than the ATP depleted 20S proteasome activity.

K48-linked ubiquitinated proteins are targets for proteasomal degradation and accumulation of K48-linked ubiquitinated proteins may indicate an increase of damaged proteins and/ or changes in proteasomal activity $(13,26,27)$. Degradation of K48-linked ubiquitinated proteins requires functional $26 \mathrm{~S}$ proteasome. In our data, $\mathrm{H}_{2} \mathrm{O}_{2}$ induced decrease in 20S+26S proteasome activities correlated with an increase in K48linked ubiquitinated proteins in K562, U251, DU145 and HepG2C3A cell lines.

When we go into detail with the data, 20S and 20S+26S proteasome activities decreased in $\mathrm{K} 562$ cells in $0 \mathrm{~h}$ time points when compared to control (PBS). Immediate response in ATP stimulated condition was more significant when compared to ATP depleted condition. In $3 \mathrm{~h}$ time point, both $20 \mathrm{~S}$ and $20 \mathrm{~S}+26 \mathrm{~S}$ proteasome activities declined in K562 cell line (Figure 1a). A significant decrease was detected in $20 \mathrm{~S}$ and $20 S+26 S$ proteasome activities in late response when compared to early response $(p<0.001)$. Due to decreased 20S+26S proteasome activity, K48-linked ubiquitinated proteins increased $\sim 2$-times in 0 h time point and $\sim 4$-times in $3 \mathrm{~h}$ time point following $\mathrm{H}_{2} \mathrm{O}_{2}$ treatment in $\mathrm{K} 562$ cell line (Figure 1b).

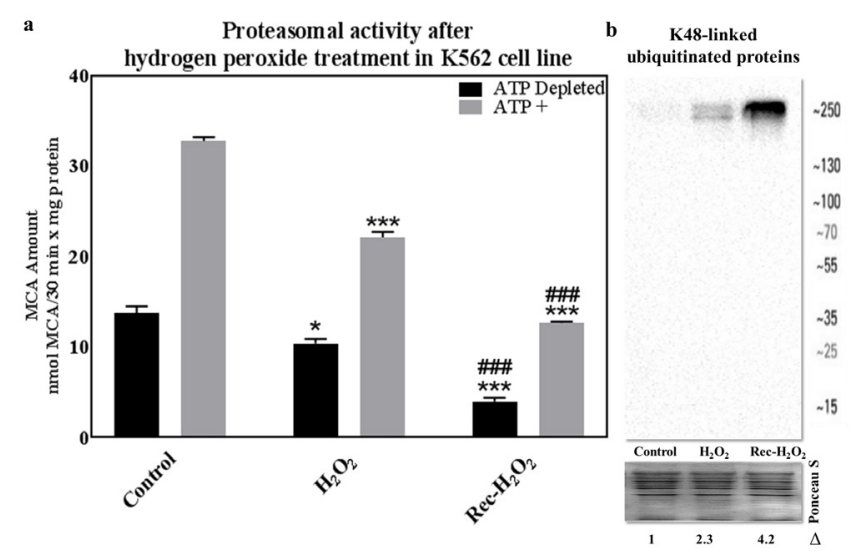

Figure 1. Proteasomal degradation and K48-linked protein ubiquitination in $\mathrm{K562}$ cells at $\mathrm{Oh}\left(\mathrm{H}_{2} \mathrm{O}_{2}\right)$ and $3 \mathrm{~h}\left(\mathrm{Rec}-\mathrm{H}_{2} \mathrm{O}_{2}\right)$ time points. a. ATP depleted degradation represents the activity of $20 \mathrm{~S}$ proteasome, whereas ATP+ (ATP stimulated) degradation is indicative of $20 \mathrm{~S}+26 \mathrm{~S}$ proteasome activities. Values are the mean \pm S.D. of three experiments. ${ }^{*} p<0.05$ vs. control group, ${ }^{* * *} p<0.001$ vs. control group, ${ }^{\#} p<0.001$ vs. $\mathrm{H}_{2} \mathrm{O}_{2}$ group. b. Representative immunoblot of K48-linked protein ubiquitination.

In U251 cells, $\mathrm{H}_{2} \mathrm{O}_{2}$ treatment decreased $20 \mathrm{~S}$ proteasome activity ( $p<0.05$ vs control) but did not change 20S+26S proteasome activity in immediate response (0h time point). In 3h time point, both $20 \mathrm{~S}$ and $20 \mathrm{~S}+26 \mathrm{~S}$ proteasome activities decreased significantly when compared to the control group (Figure 2a). A significant decrease was detected in 20S+26S proteasome activity in late response when compared to early response $(p<0.01)$. K48-linked ubiquitinated protein levels of $U 251$ cells did not change as an immediate response since $20 S+26 S$ proteasome activities did not change. But K48linked ubiquitinated protein levels increased $\sim 4$-times in $3 \mathrm{~h}$ time point (Figure $2 b$ ).

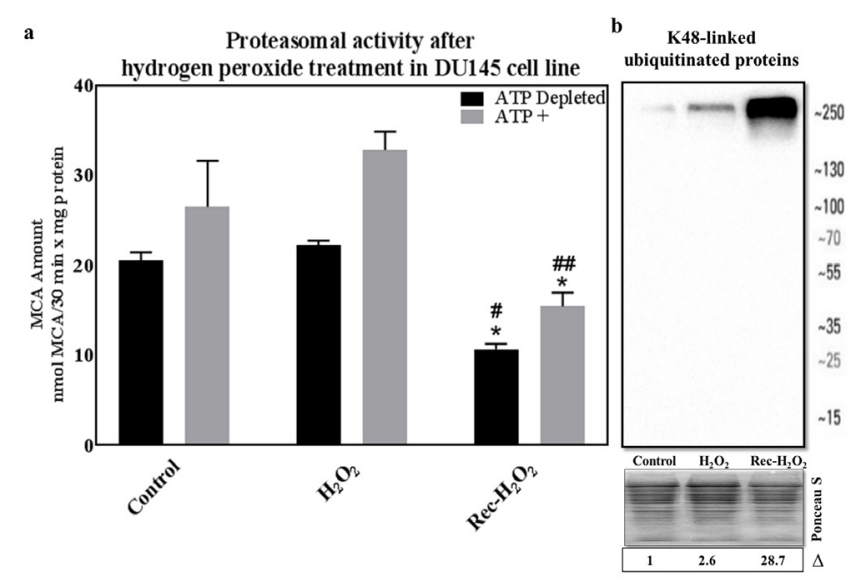

Figure 2. Proteasomal degradation and $K 48$-linked protein ubiquitination in $\mathrm{U} 251$ cells at $\mathrm{Oh}\left(\mathrm{H}_{2} \mathrm{O}_{2}\right)$ and $3 \mathrm{~h}\left(\mathrm{Rec}-\mathrm{H}_{2} \mathrm{O}_{2}\right)$ time points. a. ATP depleted degradation represents the activity of $20 S$ proteasome, whereas ATP+ (ATP stimulated) degradation is indicative of $205+265$ proteasome activities. Values are the mean \pm S.D. of three experiments. ${ }^{*} p<0.05$ vs. control group, ${ }^{* *} p<0.01$ vs. control group. ${ }^{\# p} p<0.01$ vs. $\mathrm{H}_{2} \mathrm{O}_{2}$ group. b. Representative immunoblot of K48-linked protein ubiquitination. 
Immediate response (Oh time point) in DU145, HepG2C3A and MCF7 cell lines were not significant in both 20S and 20S+26S proteasome activities. $20 S$ and $20 S+26 S$ proteasome activities significantly decreased in these DU145 ( $p<0.05$ and $p<0.01)$, HepG2C3A ( $p<0.01$ and $p<0.001)$ and MCF7 $(p<0.001$ and $p<0.001)$ cells in $3 \mathrm{~h}$ time point showing the late response of these cells (Figure 3a, $4 a$ and $5 a$ ) K48-linked ubiquitinated protein levels increased $\sim 2$-times in Oh time point in DU145 cell line where K48-linked ubiquitinated protein levels did not change in 0 h time point in HepG2C3A cells. In $3 \mathrm{~h}$ time point, K48-linked ubiquitinated protein levels increased $\sim 28$-times in DU145 cells and $\sim 5$-times in HepG2C3A cells (Figure 3b, $4 b$ ). K48-linked ubiquitinated protein levels in MCF7 cells did not show any significant change in any time point (Figure $5 b$ ).

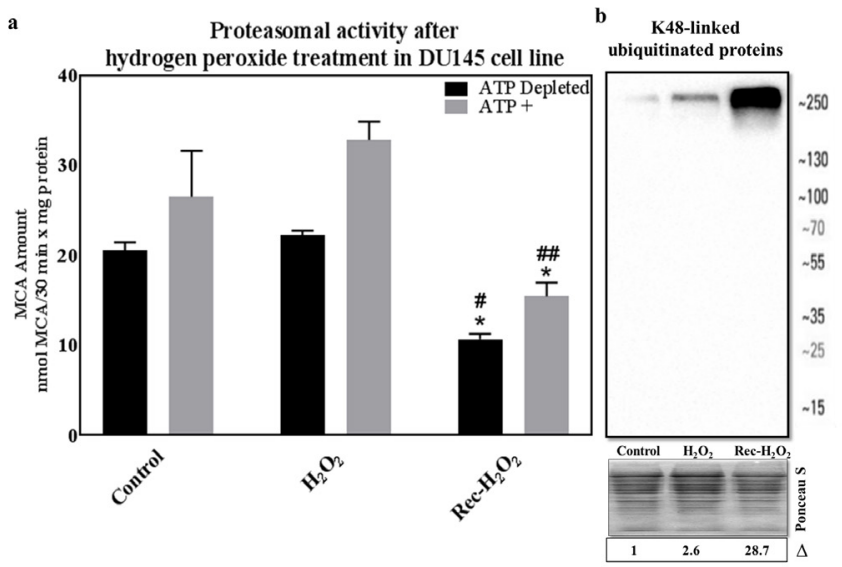

Figure 3. Proteasomal degradation and K48-linked protein ubiquitination in DU145 cells at $\mathrm{Oh}\left(\mathrm{H}_{2} \mathrm{O}_{2}\right)$ and $3 \mathrm{~h}\left(\mathrm{Rec}-\mathrm{H}_{2} \mathrm{O}_{2}\right)$ time points. a. ATP depleted degradation represents the activity of 205 proteasome, whereas ATP+ (ATP stimulated) degradation is indicative of $20 \mathrm{~S}+26 \mathrm{~S}$ proteasome activities. Values are the mean \pm S.D. of three experiments. ${ }^{*} p<0.05$ vs. control group, $" p<0.05$ vs. $\mathrm{H}_{2} \mathrm{O}_{2}$ group, ${ }^{\#} p<0.01$ vs. $\mathrm{H}_{2} \mathrm{O}_{2}$ group. b. Representative immunoblot of $K 48$-linked protein ubiquitination.

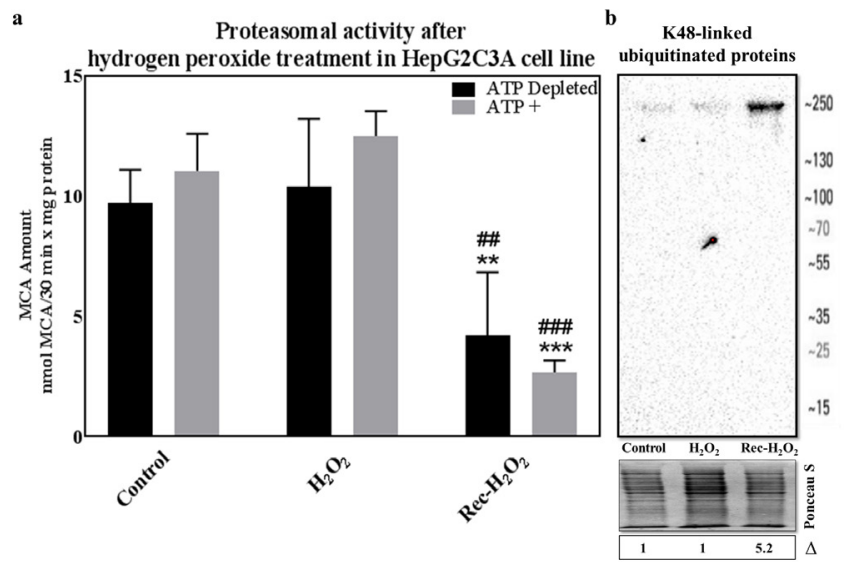

Figure 4. Proteasomal degradation and K48-linked protein ubiquitination in HepG23C3A cells at Oh $\left(\mathrm{H}_{2} \mathrm{O}_{2}\right)$ and $3 \mathrm{~h}\left(\operatorname{Rec}-\mathrm{H}_{2} \mathrm{O}_{2}\right)$ time points. a. ATP depleted degradation represents the activity of 205 proteasome, whereas ATP+ (ATP stimulated) degradation is indicative of $205+265$ proteasome activities. Values are the mean \pm S.D. of three experiments. ${ }^{* *} p<0.01$ vs. control group, ${ }^{* * *} p<0.001$ vs. control group, ${ }^{\#} p<0.01$ vs. $\mathrm{H}_{2} \mathrm{O}_{2}$ group, ${ }^{\# \#} p<0.001$ vs. $\mathrm{H}_{2} \mathrm{O}_{2}$ group. b. Representative immunoblot of K48-linked protein ubiquitination.

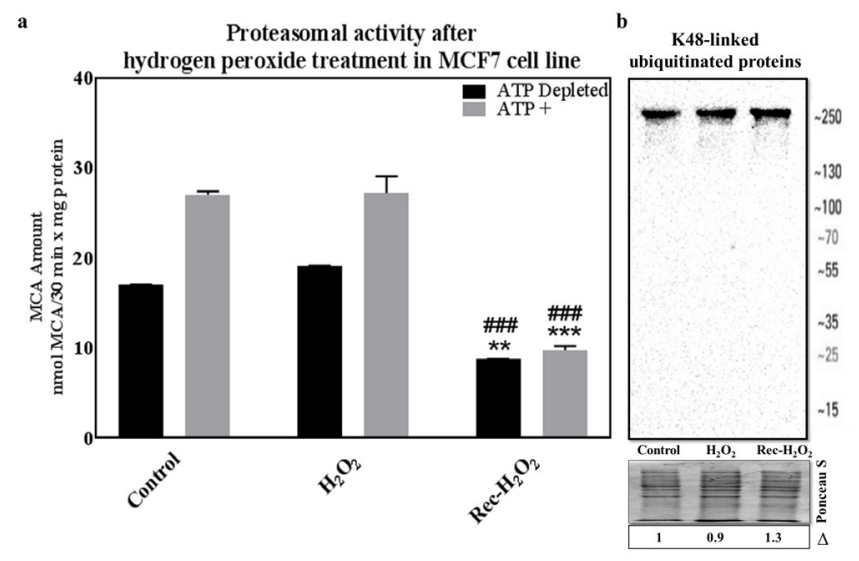

Figure 5. Proteasomal degradation and K48-linked protein ubiquitination in MCF-7 cells at Oh $\left(\mathrm{H}_{2} \mathrm{O}_{2}\right)$ and $3 \mathrm{~h}\left(\operatorname{Rec}-\mathrm{H}_{2} \mathrm{O}_{2}\right)$ time points. a. ATP depleted degradation represents the activity of 205 proteasome, whereas ATP+ (ATP stimulated) degradation is indicative of $20 \mathrm{~S}+26 \mathrm{~S}$ proteasome activities. Values are the mean \pm S.D. of three experiments. ${ }^{* *} p<0.01$ vs. control group, ${ }^{* * *} p<0.001$ vs. control group, ${ }^{\# \#} p<0.001$ vs. $\mathrm{H}_{2} \mathrm{O}_{2}$ group. $b$. Representative immunoblot of K48-linked protein ubiquitination.

\section{DISCUSSION}

Under normal conditions, cells maintain a balance between ROS levels and antioxidant systems. However, under increased oxidative stress conditions, balance is disturbed and accumulated ROS cause damage in cellular macromolecules such as lipids, proteins, carbohydrates and nucleic acids $(28,29)$. Such oxidatively damaged macromolecules can disrupt important cellular processes. Among these macromolecules, oxidatively damaged proteins and formed protein aggregates lead disturbances in many molecular pathways and they can inhibit proteasome activity (30). Thus, it is important to remove oxidatively damaged proteins by the proteasomal system and lysosomal pathways to maintain cellular protein homeostasis $(31,32)$. Oxidative stress can modulate the proteasome activity to recycle oxidatively damaged proteins and maintain cellular health. It was suggested that oxidation of proteins increases the hydrophobicity of the proteins and makes them ideal substrates for the proteasome. Therefore oxidized proteins are degraded mainly through the $20 \mathrm{~S}$ proteasome in an ATP and ubiquitin independent manner $(7,15)$. It was shown that oxidative stress causes reduction of proteasome activity and up-regulation of proteasomal component synthesis and induction of dissociation of $26 \mathrm{~S}$ proteasome complex into $19 \mathrm{~S}$ and 205 proteasomes give rise to the 20 S proteasomes (3335). It is known that K48-linked ubiquitination targets the proteins for proteasomal degradation and accumulation of K48-linked ubiquitinated proteins may indicate alterations in $26 \mathrm{~S}$ proteasome activity and/or increased proteotoxic stress $(26,27,36)$. As mentioned above, oxidized proteins generally do not have to be ubiquitinated in order to be degraded by the proteasomal system (11). For cancer cells adaptation to the oxidative stress and restoring homeostasis can protect cells from apoptotic and/or necrotic cell death $(22,23)$ which is an important point for therapy resistance. 
In this study, we investigated proteasomal activity response and K48-linked protein ubiquitination changes of different cancer cell lines in two different time points following oxidative stress to see the immediate and late response. According to our results, immediate and late response following $\mathrm{H}_{2} \mathrm{O}_{2}$ induced stress presented different changes in $20 \mathrm{~S}$ and $26 \mathrm{~S}$ proteasomal activities in different cell lines.

Inhibition of proteasome in cancer treatment has been optimized in mainly hematological cancers since 2003. In our study, we used a chronic myelogenous leukemia cell line K562 as a reference. Following $\mathrm{H}_{2} \mathrm{O}_{2}$ treatment, ATP depleted $20 \mathrm{~S}$ proteasome activities decreased only in $\mathrm{K} 562$ and U251 cell lines as immediate response when compared to control (Oh time point), (Figure 1a and 2a). On the other hand, K562 cells were the only cells that ATP stimulated $20 \mathrm{~S}+26 \mathrm{~S}$ proteasome activity decreased as an immediate response following $\mathrm{H}_{2} \mathrm{O}_{2}$ treatment (Figure 1a). The immediate response of $20 \mathrm{~S}+26 \mathrm{~S}$ proteasome was much more significant when compared to $20 \mathrm{~S}$ proteasome alone showing the sensitivity of $26 \mathrm{~S}$ proteasome in $\mathrm{K} 562$ cells. This sensitive response of leukemia cells made them suitable for treatment with proteasome inhibitors for many years.

On the other hand, no changes in $20 \mathrm{~S}$ proteasome and 20S+26S proteasome activities were observed in DU145, HepG2C3A and MCF7 cell lines as immediate response. This shows the resistance of proteasome activities among stress in these cells. It has been observed that oxidative stressrelated proteasome activity impairment was compensated with an increased level of PSMA7 subunit of 20S proteasome and proteasome complexes in MCF7 cells (37). The results of a study conducted with a large number of cancer cell lines showed that cells which are especially drug-resistant and highly aggressive need high 26S proteasome activity level for survival (38). In accordance with that, in our study $26 \mathrm{~S}$ proteasome activities of aggressive cancer cells U251, DU145, HepG2C3A and MCF7 were more resistant to oxidative stress and did not show as much proteasome activity decrease as K562 cells. In our study, none of the cancer cell lines showed increased proteasomal activity after $3 \mathrm{~h}$ of incubation when compared with the immediate response. Also, 20S+26S proteasomal activities showed a decline in $3 \mathrm{~h}$ time point and due to this decline in $26 \mathrm{~S}$ proteasome activity, K48-linked protein ubiquitination levels increased in all cell lines. In accordance with that, in a recent study protein ubiquitination levels were measured after 0.5 and 16 h of peroxide treatments in WM-451 melanoma cells and, similar to our results, ubiquitination levels showed increase in a time-dependent manner (39). Reports are showing that proteasome activity and proteasomal content could be restored following $6-24 \mathrm{~h}$ of oxidative stress $(9,34,35,40)$. According to our results, both $20 \mathrm{~S}$ and $26 \mathrm{~S}$ proteasomal activities could not be restored to the basal level after $3 \mathrm{~h}$ of recovery and they rather showed decline. These results and recent works indicate that cells cannot restore their proteasomal activity in such a short period of time.
Consistent with our observations, oxidative stress caused reduction in proteasome activity has been reported in different cell types. In ARPE-19 cell line, high levels of $\mathrm{H}_{2} \mathrm{O}_{2}$ or prolonged exposure to $\mathrm{H}_{2} \mathrm{O}_{2}$ resulted in greater decrease in the proteasome activity and increase of ubiquitin conjugates. The authors concluded that proteasomal degradation is more susceptible to oxidative stress than the ubiquitin-conjugating enzymes (41). Reinheckel et al. (2000), demonstrated that $20 \mathrm{~S}$ proteasome is more resistant to oxidative stress than $26 \mathrm{~S}$ proteasome in $\mathrm{K} 562$ cells and after $24 \mathrm{~h}$ of recovery time $26 \mathrm{~S}$ proteasome reconstitution was observed (35). Also in our study $20 \mathrm{~S}$ proteasome activity of K562 cells was more resistant to oxidative stress. Cancer cells rely on enhanced proteasomal activity for survival (42). Proteasome is a target for oxidative stress and oxidative inactivation of the proteasomal system can be a strategy for cancer therapy.

\section{CONCLUSION}

Our results present direct evidence that several cancer cell lines show different responses in proteasomal activity and different K48-linked protein ubiquitination levels in response to oxidative stress. Taken together, our data lead the conclusion that proteasome inhibition for cancer therapy should be considered for different cancer types according to their proteasomal response in stress conditions. In addition, the clinical approach for proteasome targeted therapy can be designed according to this truth.

\section{Acknowledgment}

This work was supported by Marmara University Research Fund SAG-B-130.319.0089.

\section{REFERENCES}

[1] Wang $X$, Liang $Z$, Huang $H$, Liang W. Principles of ethics review on traditional medicine and the practice of institute review board in China. Chin J Integr Med 2011; 17:631-634.

[2] Epstein T, Gatenby RA, Brown JS. The Warburg effect as an adaptation of cancer cells to rapid fluctuations in energy demand. PLoS One 2017; 12: e0185085.

[3] Liberti M V., Locasale JW. The Warburg Effect: How Does it Benefit Cancer Cells? Trends Biochem Sci 2016; 41:211-218.

[4] Sena LA, Chandel NS. Physiological Roles of Mitochondrial Reactive Oxygen Species. Mol Cell 2012; 48: 158-167.

[5] Locasale JW, Cantley LC. Metabolic flux and the regulation of mammalian cell growth. Cell Metab 2011; 14(4):443-451.

[6] Sullivan LB, Chandel NS. Mitochondrial reactive oxygen species and cancer. Cancer Metab 2014; 2(1):17.

[7] Davies KJA. Degradation of oxidized proteins by the $20 \mathrm{~S}$ proteasome. Biochimie 2001; 83(3-4):301-310.

[8] Breusing N, Grune T. Regulation of proteasome-mediated protein degradation during oxidative stress and aging. Biol Chem 2008; 389(3):203-209.

[9] Grune T, Reinheckel T, Davies KJ. Degradation of oxidized proteins in mammalian cells. FASEB J 1997; 11(7):526-534. 
[10] Jung T, Catalgol B, Grune T. The proteasomal system. Molecular Aspects of Medicine 2009; 30:191-296.

[11] Jung T, Grune T. The proteasome and the degradation of oxidized proteins: part I-structure of proteasomes. Redox Biol 2013; 1(1):178-182.

[12] Glickman $\mathrm{MH}$, Ciechanover A. The ubiquitin-proteasome proteolytic pathway: destruction for the sake of construction. Physiol Rev 2002; 82(2):373-428.

[13] Xu P, Duong DM, Seyfried NT, Cheng D, Xie Y, Robert J, et al. Quantitative proteomics reveals the function of unconventional ubiquitin chains in proteasomal degradation. Cell 2009; 137(1):133-45.

[14] Strickland E, Hakala K, Thomas PJ, DeMartino GN. Recognition of misfolding proteins by PA700, the regulatory subcomplex of the 26 S proteasome. J Biol Chem 2000; 275(8):5565-5572.

[15] Shang F, Taylor A. Ubiquitin-proteasome pathway and cellular responses to oxidative stress. Free Radic Biol Med 2011; 51(1):5-16.

[16] Schmidt M, Finley D. Regulation of proteasome activity in health and disease. Biochim Biophys Acta (BBA)-Molecular Cell Res 2014; 1843(1):13-25.

[17] Lander GC, Estrin E, Matyskiela ME, Bashore C, Nogales E, Martin A. Complete subunit architecture of the proteasome regulatory particle. Nature 2012; 482(7384):186.

[18] Sitte N, Merker K, Grune T. Proteasome-dependent degradation of oxidized proteins in MRC-5 fibroblasts. FEBS Lett 1998; 440:399-402.

[19] Grune T, Catalgol B, Licht A, Ermak G, Pickering AM, Ngo JK, et al. HSP70 mediates dissociation and reassociation of the 26S proteasome during adaptation to oxidative stress. Free Radic Biol Med 2011; 51(7):1355-1364.

[20] Chen L, Madura K. Increased proteasome activity, ubiquitinconjugating enzymes, and eEF1A translation factor detected in breast cancer tissue. Cancer Res 2005; 65(13):5599-606.

[21] Arlt A, Bauer I, Schafmayer C, Tepel J, Müerköster SS, Brosch $M$, et al. Increased proteasome subunit protein expression and proteasome activity in colon cancer relate to an enhanced activation of nuclear factor E2-related factor 2 (Nrf2). Oncogene 2009; 28:3983-3996.

[22] Buttke TM, Sandstrom PA. Oxidative stress as a mediator of apoptosis. Immunol Today 1994; 15(1):7-10.

[23] Boldyrev AA. Discrimination between apoptosis and necrosis of neurons under oxidative stress. Biochem C/C BIOKHIMIIA 2000; 65(7):834-42.

[24] Adams J. The proteasome: structure, function, and role in the cell. Cancer Treat Rev 2003; 29:3-9.

[25] Ertel A, Verghese A, Byers SW, Ochs M, Tozeren A. Pathwayspecific differences between tumor cell lines and normal and tumor tissue cells. Mol Cancer 2006; 5(1):55.

[26] Ikeda F, Dikic I. Atypical ubiquitin chains: new molecular signals. "Protein Modifications: Beyond the Usual Suspects" review series. EMBO Rep 2008; 9:536-542.
[27] Launay N, Ruiz M, Fourcade S, Schlüter A, Guilera C, Ferrer $\mathrm{I}$, et al. Oxidative stress regulates the ubiquitin-proteasome system and immunoproteasome functioning in a mouse model of X-adrenoleukodystrophy. Brain 2013; 136(3):891-904.

[28] Apel K, Hirt H. Reactive oxygen species: metabolism, oxidative stress, and signal transduction. Annu Rev Plant Biol 2004; 55:373-399.

[29] Valko M, Leibfritz D, Moncol J, Cronin MTD, Mazur M, Telser J. Free radicals and antioxidants in normal physiological functions and human disease. Int J Biochem Cell Biol 2007; 39(1):44-84.

[30] Bence NF, Sampat RM, Kopito RR. Impairment of the ubiquitinproteasome system by protein aggregation. Science 2001; 292(5521):1552-1555.

[31] Tyedmers J, Mogk A, Bukau B. Cellular strategies for controlling protein aggregation. Nat Rev Mol Cell Biol 2010; 11(11):777-788.

[32] Lefaki M, Papaevgeniou N, Chondrogianni N. Redox regulation of proteasome function. Redox Biol 2017; 13:452-458.

[33] Livnat-Levanon N, Kevei É, Kleifeld O, Krutauz D, Segref A, Rinaldi $\mathrm{T}$, et al. Reversible $26 \mathrm{~S}$ proteasome disassembly upon mitochondrial stress. Cell Rep 2014; 7:1371-1380.

[34] Wang X, Yen J, Kaiser P, Huang L. Regulation of the 26S proteasome complex during oxidative stress. Sci Signal 2010; 3(151):ra88-ra88.

[35] Reinheckel T, Ullrich O, Sitte N, Grune T. Differential impairment of $20 \mathrm{~S}$ and $26 \mathrm{~S}$ proteasome activities in human hematopoietic K562 cells during oxidative stress. Arch Biochem Biophys 2000; 377: 65-68.

[36] Grice GL, Nathan JA. The recognition of ubiquitinated proteins by the proteasome. Cell Mol Life Sci 2016; 73(18):3497-506.

[37] Li D, Dong Q, Tao Q, Gu J, Cui Y, Jiang X, et al. c-Abl regulates proteasome abundance by controlling the ubiquitinproteasomal degradation of PSMA7 subunit. Cell Rep 2015; 10(4):484-496.

[38] Tsvetkov P, Adler J, Myers N, Biran A, Reuven N, Shaul Y. Oncogenic addiction to high 265 proteasome level. Cell Death Dis 2018;9(7):1-14.

[39] Kästle $M$, Reeg S, Rogowska-Wrzesinska A, Grune T. Chaperones, but not oxidized proteins, are ubiquitinated after oxidative stress. Free Radic Biol Med 2012; 53(7):14681477.

[40] Aiken CT, Kaake RM, Wang X, Huang L. Oxidative stressmediated regulation of proteasome complexes. Mol Cell Proteomics 2011; 10(5):R110-006924.

[41] Zhang $X$, Zhou J, Fernandes AF, Sparrow JR, Pereira P, Taylor $A$, et al. The Proteasome: A Target of Oxidative Damage in Cultured Human Retina Pigment Epithelial Cells. Investig Opthalmology Vis Sci 2008; 49:3622-3630.

[42] Deshaies RJ. Proteotoxic crisis, the ubiquitin-proteasome system, and cancer therapy. BMC Biol 2014; 12(1):1-14. 